\title{
Multifunctional Composites for Future Energy Storage in Aerospace Structures
}

\author{
Till Julian Adam ${ }^{1, *}$, Guangyue Liao ${ }^{1}$, Jan Petersen ${ }^{1}$, Sebastian Geier ${ }^{1}$ (D), Benedikt Finke ${ }^{2}$, \\ Peter Wierach ${ }^{1}$, Arno Kwade ${ }^{2}$ (D) and Martin Wiedemann ${ }^{1}$ \\ 1 German Aerospace Center (DLR e. V.), Institute of Composite Structures and Adaptive Systems, \\ Lilienthalplatz 7, 38108 Braunschweig, Germany; Guangyue.Liao@dlr.de (G.L.); Jan.Petersen@dlr.de (J.P.); \\ Sebastian.Geier@dlr.de (S.G.); Peter.Wierach@dlr.de (P.W.); Martin.Wiedemann@dlr.de (M.W.) \\ 2 Technische Universität Braunschweig, Institute for Particle Technology, Volkmaroder Str. 5, \\ 38104 Braunschweig, Germany; b.finke@tu-braunschweig.de (B.F.); a.kwade@tu-braunschweig.de (A.K.) \\ * Correspondence: Till.Adam@dlr.de; Tel.: +49-531-295-2840
}

Received: 15 December 2017; Accepted: 29 January 2018; Published: 2 February 2018

\begin{abstract}
Multifunctionalization of fiber-reinforced composites, especially by adding energy storage capabilities, is a promising approach to realize lightweight structural energy storages for future transport vehicles. Compared to conventional energy storage systems, energy density can be increased by reducing parasitic masses of non-energy-storing components and by benefitting from the composite meso- and microarchitectures. In this paper, the most relevant existing approaches towards multifunctional energy storages are reviewed and subdivided into five groups by distinguishing their degree of integration and their scale of multifunctionalization. By introducing a modified range equation for battery-powered electric aircrafts, possible range extensions enabled by multifunctionalization are estimated. Furthermore, general and aerospace specific potentials of multifunctional energy storages are discussed. Representing an intermediate degree of structural integration, experimental results for a multifunctional energy-storing glass fiber-reinforced composite based on the ceramic electrolyte $\mathrm{Li}_{1.4} \mathrm{Al}_{0.4} \mathrm{Ti}_{1.6}\left(\mathrm{PO}_{4}\right)_{3}$ are presented. Cyclic voltammetry tests are used to characterize the double-layer behavior combined with galvanostatic charge-discharge measurements for capacitance calculation. The capacitance is observed to be unchanged after 1500 charge-discharge cycles revealing a promising potential for future applications. Furthermore, the mechanical properties are assessed by means of four-point bending and tensile tests. Additionally, the influence of mechanical loads on the electrical properties is also investigated, demonstrating the storage stability of the composites.
\end{abstract}

Keywords: structural energy storages; multifunctional power composites; $\mathrm{Li}_{1.4} \mathrm{Al}_{0.4} \mathrm{Ti}_{1.6}\left(\mathrm{PO}_{4}\right)_{3}$ solid electrolyte; electrical properties; mechanical properties

\section{Introduction}

Electric-powered vehicles (in general) have many advantages compared to those based on combustion engines. First of all, being free of local emissions and presenting the possibility of covering energy demands with clean renewable energy are the main drivers of the energy revolution and the booming e-mobility sector. Besides these key features, there are several technical and economic aspects, such as high efficiencies of energy conversion, low noise emission, high starting torques, high power-to-weight ratios, high reliability, low maintenance costs, the possibility of energy recuperation or harvesting or of gearless continuous variable transmissions, that make electrical systems interesting [1].

Whereas electric-powered rail vehicles found their way into public transportation since the Gross Lichterfelde Tramway (1880) [2] was established and even though the first battery-powered cars were invented at the same time (e.g., the Flocken Elektrowagen, 1888 [3]), it took more than 100 years, until the 1990s, for electric cars to see a boost [4]. Thereby, the invention and continuous development of 
lithium-based batteries plays a key-role [5]. Regarding air transportation, the high weight (low specific energy density) of the state-of-the-art battery systems still inhibits major progress. Whereas the electric system weight plays a subordinate role in the case of ground vehicles, aircraft performance is very sensible to mass. Furthermore, in aviation, typical trip distances to be reached are much larger, and safety requirements to be met are higher [6].

Although there are several quite prestigious manned battery-, fuel cell-, supercapacitor- or solar cell-based electric flight projects (such as the MB-E1 (1973) [7], Boeing FCD (2008) [8], Pipistrel Taurus Electro G2 (2011) [9], Solar Impulse [10], Airbus E-Fan (2014) [11], Magnus Aircraft effusion 2 (2014) [12], HY4 (2016) [13], Siemens Extra 330LE (2017) [14], or the NASA X-57 (2017) [15]), it is still a long way towards pure electric or hybrid regional, middle-, and long-distance passenger transportation. Besides the necessity of improving the energy density of storage devices, a holistic rethinking of common aircraft designs is required to achieve a multidisciplinary coupling and synergistic integration of the electric propulsion systems with the aerodynamics, aeroelasticity, or flight control [1].

As the weight of conventional electric energy storage (batteries and supercapacitors) is one of the largest obstacles to overcome, extensive efforts on increasing energy density are being made. In addition to chemistry- and physics-oriented work on improving electrolytes and electrode materials, extensive research on multifunctional energy storage designs has been put forth $[16,17]$. The underlying idea of this approach is to significantly improve the system level specific energy by adding energy storing capabilities to structural-then multifunctional-components. As the functional weight of the energy storing systems, including enclosures, mechanical protection, and monitoring electronics can be twice the weight of the actual cells $[18,19]$, structure integration can enable significant weight savings. The multifunctionalization of composites is seen as a chance to realize competitive electric road vehicles and energy-saving future aircrafts $[20,21]$.

In this paper, the concept of multifunctional composite materials is addressed, focusing on structural energy storage. Firstly, a brief overview on the state of the art of multifunctional energy-storing composite materials is given, covering the full range of approaches and differentiating them by their degree of integration and their scale of multifunctionalization. Secondly, in addition to outlining the general and aerospace-specific advantages of structural energy storages, a modified range equation for battery-powered electric aircrafts is introduced to illustrate the potential range extensions in aviation. Thirdly, representing an intermediate degree of structural integration, a multifunctional energy-storing glass fiber-reinforced composite based on the ceramic electrolyte $\mathrm{Li}_{1.4} \mathrm{Al}_{0.4} \mathrm{Ti}_{1.6}\left(\mathrm{PO}_{4}\right)_{3}$ (LATP) is fabricated and characterized experimentally.

\section{Multifunctional Energy-Storing Composites}

In engineering applications, the general concept of multifunctionality [22-26] is understood as a holistic and multidisciplinary approach of optimizing a system with respect to the main design drivers (such as weight or volume). In contrast to optimizing the individual system components usually featuring distinct functionalities, multifunctional components are designed to realize multiple (at least two) predetermined functions which improves weight and volumetric efficiencies and enables performance enhancements [23]. Qidwai et al. [24] described the concept as a material level counterpart of multidisciplinary system design. Its multidisciplinary nature is best illustrated by Christodoulou et al. [25], who published an early review of the first generation of multifunctional material systems: whereas materials science states the framework, biology contributes a diverse repertoire of multifunctional materials, mathematics provides the tools for optimizing, physics provides the fundamental laws, and design enables innovative architectures for arranging features and attributes. Thereby, one of the main challenges is to achieve synergistic, not parasitic combinations of properties. The most important structural and non-structural properties and functions reviewed by Gibson [26] are electrical and thermal conductivity, sensing, actuation, energy harvesting and storage, self-healing capability, electromagnetic interference shielding, recyclability or biodegradability. 
Structural energy storage was first investigated under the auspices of the DARPA Synthetic Multifunctional Materials Program in the early 2000s [25]. Since then, a variety of approaches has been established ranging from the structural integration of standard battery or capacitor cells to the microscaled functionalization of the fiber-reinforced laminate constituents, as depicted in Figure 1a. In all cases, weight saving or increasing weight-specific energy are the main drivers. Possible weight benefits were demonstrated by Wetzel [27] by means of an exemplary ground vehicle. Wetzel introduced the structural mass efficiency $\sigma_{s}$ to represent a structural property, such as stiffness or strength, relative to the conventional solely load carrying composite structure $\left(\sigma_{s}=1\right)$. Analogously, an energy mass efficiency measure $\sigma_{e}$, which is $\sigma_{e}=1$ in case of a conventional battery, was defined. Accordingly, regarding conventional systems with a strict functional separation, it is $\sigma_{s}^{\text {battery }}=\sigma_{e}^{\text {structure }}=0$. Then, according to Wetzel [27], the total system mass $m_{\text {total }}$ can be calculated in dependence of both efficiency factors and masses of the original structure ( $\left.m_{\text {structure }}\right)$ and the battery $\left(m_{\text {battery }}\right)$ :

$$
m_{\text {total }}=m_{\text {structure }}+\left(1-\sigma_{s}^{\text {battery }}\right) \cdot\left(m_{\text {battery }} / \sigma_{e}^{\text {battery }}\right)
$$

The relationship is illustrated for different structural and energy mass efficiencies in Figure $1 \mathrm{~b}$. Whereas the total mass of the exemplary conventional system is $m_{\text {total }}=1500 \mathrm{~kg}$, the maximum weight saving results in the unrealistic case of an ideal structural battery with full energy and structural performance. With compromised configurations, however, reasonable weight savings may be achieved as well.

Whereas a comprehensive and technically detailed review on structural batteries and supercapacitors was published by Asp and Greenhalgh [16], the state of the art of structural energy storage is briefly reviewed from another perspective in Section 2.1. Not differentiating the type of storage (electrochemical or physical) and without providing in-depth information, the existing concepts are distinguished by their degree and scale of multifunctionalization.

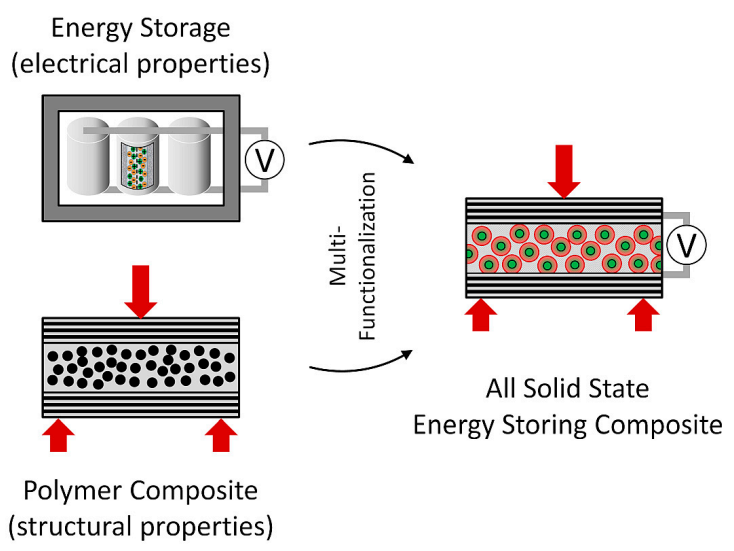

(a)

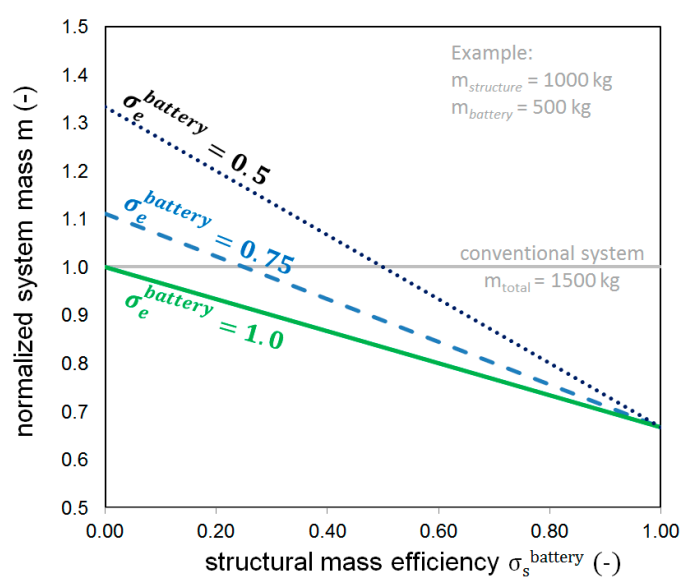

(b)

Figure 1. (a) Concept of multifunctional energy storing cross-ply composites with functionalized constituents; (b) calculated system mass reduction according to Wetzel [27].

\subsection{Scales and Degrees of Structural Integration}

In this paper, two expressions are introduced and illustrated in Figure 2 helping to describe the functional integration characteristics of energy storages. Firstly, the scale of multifunctionalization refers to the geometrical organization levels of composite laminates. According to common definitions of the scales of observation (e.g., for observing damages [28]), the smallest scale is the microscale concerning all details of the heterogeneous structure (single fiber, fiber-matrix interface). The mesoscale represents the scale of the unidirectional single layer, and the macroscale concerns the overall laminate. 
Above that scale, structures made from fiber-reinforced laminates range on the component level. The second relevant expression, the degree of integration or multifunctionalization is used as a rough measure for the proportion a battery is integrated into a fiber-reinforced structure. Comparable to the efficiency measures defined by Wetzel [27], a conventional non-load-carrying battery corresponds to zero degree of integration (functional separation). A low level of multifunctionalization is reached by omitting non-energy-saving peripheral components (such as enclosures), by integrating the bare standard cells into a structure (e.g., aircraft omega stringer).

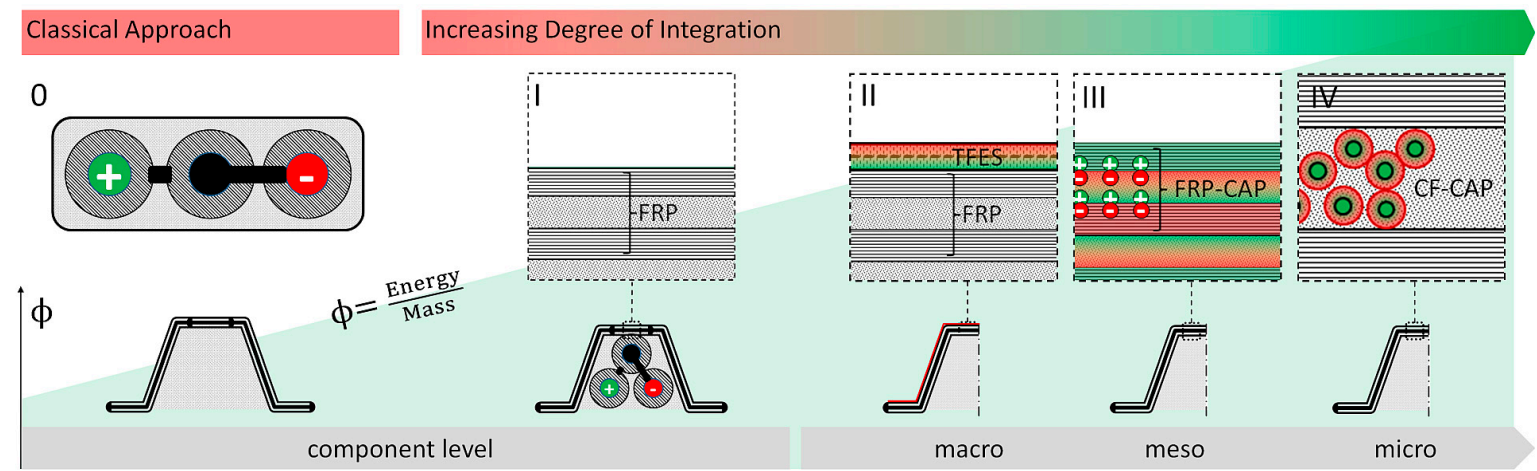

Figure 2. Concept and scales of multifunctional structural energy storage demonstrated for an aircraft fuselage omega stringer: classical functional separation (0), integration of non-load-carrying conventional cells (I), integrated thin-film energy storages (TFES) (II), structural laminate capacitors (FRP-CAP) (III) and microscaled coaxial fiber capacitors (CF-CAP) (IV).

Towards higher degrees of structural integration, the energy-storing capability is gradually transferred to the composite laminate, for example by bonding thin-film energy storages (TFES, batteries or capacitors) onto the surface of the laminate or by integrating them into it (II). Storing energy in the actual laminate by assigning functions to the individual single layers or constituents (e.g., with carbon fiber single layers acting as electrodes, glass fiber mats acting as separators, or the matrix material acting as a solid electrolyte) means a further increase of the degree of multifunctionalization (III). In the authors' opinion, the highest degree possible corresponds to assigning energy storing capabilities to the single fibers (e.g., coaxial fiber capacitors) which are the actual load-bearing elements (IV). In contrast to multifunctionalization on the mesoscale, ion transport distances (between fibers or within a fiber-surrounding nanostructured capacitor architecture) can be reduced significantly by using the microscaled architecture of the composite. Furthermore, regarding capacitive energy storage, the total fiber surface in combination with an additional surface enlargement, for example by means of nanoparticles, is assumed to provide significant capacitances. As illustrated in the figure, the degree of integration or multifunctionalization and the scale (in terms of the physical dimensions of the functionalized components) are in an inverse relation. Increasing the degree of energy storage integration requires a lower scale functionalization and vice versa. From a theoretical point of view, the energy density is assumed to behave similarly to the degree of multifunctionalization because of two reasons. Firstly, assuming that the mass of the laminate (more specifically, its mechanical properties) is not affected by multifunctionalization, energy density increases as a result of saving parasitic weights of the battery peripheral structures. Secondly, the functionalization of the microscaled constituents and further surface enlargement by nanomodification can significantly increase the storage capacity.

\subsection{State of the Art of Structural Energy Storage}

The following sections provide a short overview of the state of the art of structural integration of energy storage functionalities into load-bearing structures. Thereby, reviewed approaches are distinguished with respect to their degree of integration, as defined above. 


\subsubsection{Functional Separation (0)}

Functional separation denotes the common separation of energy storage (using conventional batteries) and structural tasks (carrying loads, shape retention). In fact, most electrified and commercially available ground and air vehicles are powered by means of conventional, non-load-carrying lithium-based battery systems. Usually, large numbers of devices are grouped and combined in one enclosure to provide accessibility and simple integration into the system or vehicle. In harsh contrast to the holistic concept of multifunctionalization, the individual systems (light-weight structure, high-energy-density energy storage) are optimized individually.

\subsubsection{Integrated Conventional Storages (I)}

By integrating bare battery cells into cavities and unused spaces of structural components, certain mass savings are possible. Savings, however, are limited to the masses of the enclosures which usually serve as mechanical or moisture protection or contain liquid electrolytes.

Following this approach, Ladpli et al. [19] presented a multifunctional structural battery consisting of Li-ion pouch cells embedded into high-strength CFRP (carbon fiber-reinforced polymer) and integrated sensors for battery health and status monitoring. As the anodes, cathodes, and separators of their cells were simply stacked without having any load-bearing capability, a sandwich-like architecture was built. Thereby, the batteries were stacked between the outer CFRP layers which carry in-plane as well as bending loads. Additional through-the-thickness polymer reinforcement pins were integrated to provide sufficient shear stiffness. Inbuilt sensors were used to investigate physical changes in the battery during electrical cycling. Guided wave-based ultrasound monitoring was found to improve the accuracy of the state-of-charge and state-of-health estimations. Unfortunately, no information on the system energy density was provided.

A comparable approach was presented by Thomas et al. [29,30] integrating thin lithium batteries into the foam core of a CFRP sandwich material. The multifunctional laminates were characterized regarding their energy storing capacity and flexural properties. A comparison to the monofunctional reference material revealed a decrease in strength due to a change in failure mode. The design targets regarding specific energy were not met, as the multifunctional laminates had a larger thickness compared to their monofunctional counterparts.

Generally, as the commercially available energy storages are already optimized regarding energy capacity and unit mass, the total savings and efficiency-gains provided by integrating conventional cells are not significant [17].

\subsubsection{Thin-Film-Based Approaches (II)}

Although there does not seem to be a noticeable difference between the integration of conventional (cylindrical, block, or thin-film) cells into structural components and the integration of thin-film devices into (or onto) a laminate at first glance, both approaches should be distinguished regarding the intended load-carrying function of the energy-storing cells. Whereas structure-integrated cells are for example placed in cavities or embedded in foam cores and are not necessarily intended to carry loads, this is different in the case of energy-storing thin-film layers. These, in fact, are part of the composite laminate, experience the same macroscopic strains, and add a certain structural capability depending on their mechanical properties.

Integrating thin-film energy devices as interlayers in composite structures or as an additional layer on a structure leads to a reduction of the total weight and volume. There is no need for a housing of the energy storage as the composite structure provides these functions. Using thin-film energy storages allows to lower the distance between the electrodes. This reduces the migration distance of the ions and leads to a higher ionic conductivity [31], and, therefore, to a higher power density.

Gasco and Feraboli [32] proposed a laminated composite airframe for load-bearing and electrical energy storage. They conducted investigations on embedded thin-film batteries and externally bonded 
batteries with the conclusion that this technology could be applied within a limited scope. Possible applications are micro- and mini-UAV (unmanned aerial vehicle) platforms with minimal mechanical demands. To expand the scope of application it is important to improve the mechanical properties of the thin-film battery. They found the mismatch of the mechanical properties of the battery and laminate to be a problem. Furthermore, they observed that the variation of the battery thickness induced delamination, especially in the case of multilayer stackings. With regards to the total weight, it is indispensable to look for new current substrates with lower densities [32]. In a later publication [33], the processability of embedded solid-state thin-film lithium-ion batteries was investigated to optimize the curing cycle with respect to the battery capacity retention.

Mullenax et al. [34] investigated commercial batteries laminated into a composite structure. They optimized the electrode by creating holes to get better bonding between the composite layers and therefore reached a significant increase in strength. Pereira et al. $[35,36]$ conducted research on embedding thin-film lithium energy cells $(3.6 \mathrm{~V}, 200 \mathrm{Wh} / \mathrm{kg}$, thickness: $0.15 \mathrm{~mm})$ into carbon fiber-reinforced unidirectional and cross-ply laminates. The flexural capability of the bare cell, its pressure resistance (important for autoclave curing), and the impact of cell integration on the mechanical properties were investigated. They found that battery integration did not significantly affect the elastic modulus and strength under quasi-static uniaxial loading conditions. The resulting package energy capacity was $2 \mathrm{mAh} / \mathrm{g}$, and the energy density was $8 \mathrm{Wh} / \mathrm{kg}$.

\subsubsection{Single-Ply Functionalization (III)}

Single-ply functionalization presents the first step of integration with true multifunctionality. All the necessary electrical components are substituted by a load-carrying constituent. Functionalized carbon fibers correlate for the collector and the electrode. The matrix provides ion conductivity similar to the electrolyte of conventional energy storages. An energy storage device is mostly built up as a sandwich structure made from woven carbon and glass fiber infused by a modified matrix $[27,37]$. To increase the electrical capacity (in case of a supercapacitor), the specific surface of the carbon fiber is increased, for example by means of a carbon aerogel coating, carbon nanotube (CNT) growth on the fiber surface, or by activating the fibers using potassium hydroxide $(\mathrm{KOH})$ [38-40]. The required separation layer is usually achieved by means of glass fiber because of its electrically isolating and structural characteristic [41]. On the one hand, as a glass-fiber layer strongly influences the power density, it has to be thin to reduce the distance between the electrodes. On the other hand, it is important to ensure that there is no direct contact between the electrodes to avoid electrical short circuiting. The matrix material of energy storing composites is the most ambitious part. It has to be robust to carry mechanical loads whilst providing ion movement for charge-discharge processes. This electrochemical characteristic is reached, for example, by combining ionic liquids with epoxy resins to create a bicontinuous network [38]. With increasing ion conductivity, however, stiffness decreases and vice versa. This characteristic is based on the fact that ion movement is restricted in solid electrolytes [42]. To be able to manufacture a structural composite of the sandwich type with both high stiffness and high electrical potential, new matrix materials have to be developed.

\subsubsection{Constituent Functionalization}

A microscaled approach for adding electrical energy storage capabilities to a composite structure is the coaxial integration. Each coaxial fiber system is functionalized to act as a separate energy storage. The inner electrical conductive fiber represents one electrode. It has to be robust to carry mechanical loads whilst providing an optimized surface for the application. The inner fiber is surrounded by a hollow fiber which should have the same properties as the inner one. Both fibers are separated by a porous electrically isolating layer. This ensures that there is no risk of electrical short circuiting, while simultaneously providing ion transport. This coaxial system offers the opportunity to create an energy storage device without the need of an additional separation layer. Electrical contacting, however, is an issue to be solved. Yu and Thomas developed a lab-scaled coaxial capacitor based on a 
single copper fiber with nanowires grown on its surface [43]. With the copper fiber being $0.37 \mathrm{~mm}$ in diameter, they were able to place the fiber into an outer tubular electrode, both precoated with a gel electrolyte. The setup reached a volumetric energy density of $0.55 \mathrm{mWh} / \mathrm{cm}^{3}$ and a power density of $413 \mathrm{~mW} / \mathrm{cm}^{3}$.

Leijonmarck et al. developed a battery similar to the coaxial integration. A carbon fiber was electro-coated with a methacrylate-based solid polymer acting as an electrolyte. The counter electrode was lithium metal separated by a glass fiber from the carbon fibers [44].

\subsection{General and Aerospace-Specific Potentials of Structural Energy Storage}

Various electric aircraft designs have been investigated [6,45-50], either dealing with the conversion of existing fuel-powered aircrafts to all-electric or hybrid aircrafts, or with the development of totally new aircraft designs. However, many electric aircraft designs rely on substituting the fuel-powered propulsion system by an electrical one using, for example, (heavy) conventional batteries. In contrast, Moore and Fredericks [1], who comprehensively discussed the most common misconceptions of electric aircraft development, concluded that a holistic design aiming for the synergistic integration of electric propulsion systems and energy storages plays a key role in future electric aircraft design.

With mass being a significant constraint in all aerospace applications, reducing weight clearly is the main driver for structure-integrated energy storage in future electric aircrafts. The potential benefits in terms of cruise range extension provided by the multifunctionalization of aircraft composite structure can be roughly estimated by means of a modified range equation. Assuming a constant velocity $(v=$ const.) cruise flight of duration $t$, the range $R$ of an arbitrary aircraft is

$$
R=v \cdot t
$$

With the flight time depending on the available (stored) energy $E$, the required propulsion power $P_{\text {aircraft }}$, and the overall aircraft efficiency $\eta_{\text {total }}$, the cruise range $R$ becomes

$$
R=v \cdot \frac{E \cdot \eta_{\text {total }}}{P_{\text {aircraft }}}
$$

Thereby, according to Hepperle [6], $\eta_{\text {total }}$ is the efficiency of energy conversion from battery storage to propulsive power. The power required by an aircraft is linked to its weight $m$, lift over drag ratio $L / D$, and constant cruise speed $v$ and is given by

$$
P_{\text {aircraft }}=\frac{m \cdot g}{L / D} \cdot v \text {. }
$$

By inserting (4) into (3) the flight speed vanishes, resulting in the range equation for a plane with constant mass $m_{\text {aircraft }}$ and available Energy $E$.

$$
R=E \cdot \eta_{\text {total }} \cdot \frac{1}{g} \cdot \frac{L}{D} \cdot \frac{1}{m_{\text {aircraft }}} .
$$

Assuming an all-electric battery-powered aircraft with the mass

$$
m_{\text {aircraft }}=m_{\text {structure }}+m_{\text {payload }}+m_{\text {battery }}
$$

and with the available energy being only stored in conventional batteries $E=E_{\text {battery }}$, the cruise range becomes

$$
R=E_{\text {battery }} \cdot \eta_{\text {total }} \cdot \frac{1}{g} \cdot \frac{L}{D} \cdot \frac{1}{m_{\text {structure }}+m_{\text {payload }}+m_{\text {battery }}} .
$$


As evident from Equation (7), the range can be extended by increasing the amount of stored energy, by increasing the overall efficiency, by increasing the lift to drag ratio, or by decreasing the total mass.

Based on this battery-powered electric aircraft, parts of the structure may be substituted with energy-storing composite laminates (ESCL) leading to a reduction of the conventional battery capacity and mass. In the multifunctional configuration, the same amount of energy is stored in both conventional batteries (smaller) and additional multifunctional battery storages with the proportion being described by the degree of structural integration $\Theta$ in the range between $0-1$.

$$
E=E_{E S C L}+E_{\text {battery }}^{*} \text { with } E_{E S C L}=\Theta E_{\text {battery }} \text { and } E_{\text {battery }}^{*}=(1-\Theta) E_{\text {battery }}
$$

Consequently, the required conventional battery mass is reduced to

$$
m_{\text {battery }}^{*}=(1-\Theta) \cdot m_{\text {battery }} .
$$

Assuming that the aircraft size, the payload, and the structural weight are not changed (material properties not affected by multifunctionalization), the new (lower) aircraft mass reads

$$
m_{\text {aircraft }}^{*}=m_{\text {structure }}+m_{\text {payload }}+m_{\text {battery }}^{*}
$$

This relationship, in fact, can also be derived from Equation (1) by including the mass of the payload and by setting $\sigma_{e}^{\text {battery }}=1$. Finally, by assuming that the aerodynamics and overall efficiency of the aircraft are not affected as well, the new range of the multifunctional energy storage aircraft becomes

$$
R^{*}=E \cdot \eta_{\text {total }} \cdot \frac{1}{g} \cdot \frac{L}{D} \cdot \frac{1}{m_{\text {structure }}+m_{\text {payload }}+m_{\text {battery }}^{*}} .
$$

Introducing the ratio of the original battery mass to the total mass of the aircraft $\lambda=m_{\text {battery }} / m_{\text {aircraft }}$ allows substituting the unchanged structural mass and payload via

$$
m_{\text {structure }}+m_{\text {payload }}=m_{\text {battery }} \cdot\left(\frac{1}{\lambda}-1\right) .
$$

Combining Equations (7), (9), (11), and (12) results in Equation (13) describing the dependency of the aircraft range change on the degree of structural integration and the battery weight fraction.

$$
\frac{R^{*}}{R}=\frac{1}{1-\lambda \cdot \Theta}
$$

Plotting this relation in Figure 3 illustrates the cruise range increase achieved by substituting the conventional battery for battery masses between $0 \%$ and $60 \%$ of the total aircraft mass. As the substitution reduces the total aircraft mass, increasing the degree of structural integration causes the cruise range to grow progressively. Similarly, as potential mass reductions grow with the battery mass, the cruise range also extends when the battery mass fraction is increased.

Although rather high range extensions are predicted, the estimations have to be understood as most theoretical, giving a rough impression on the order of magnitude of possible performance gains. In fact, in addition to the underlying assumptions stated before (constancy of efficiency, structural mass and payload, multifunctionalization without degrading the mechanical material properties, limitation to constant-speed cruise), the range of technically feasible battery mass fractions has to be taken in consideration, too. Concerning conventional batteries, feasible mass fractions approximately range between $10 \%$ and $40 \%$ of the total aircraft mass [6]. Thus, assuming an ideal and full battery substitution, the maximum range extensions are between $11 \%(\lambda=0.1)$ and $66 \%(\lambda=0.4)$. One further most important prerequisite, however, is that the structural energy storage is capable of covering the 
original battery capacity. In fact, regarding today's conventional aircrafts, there are lots of primary (critical load-carrying) and secondary (non-critical structural components such as aerodynamic fairings) structures (stringers, frames, floor beams, flooring, fuselage skin, linings etc.) that may conceivably be used for storing energy.

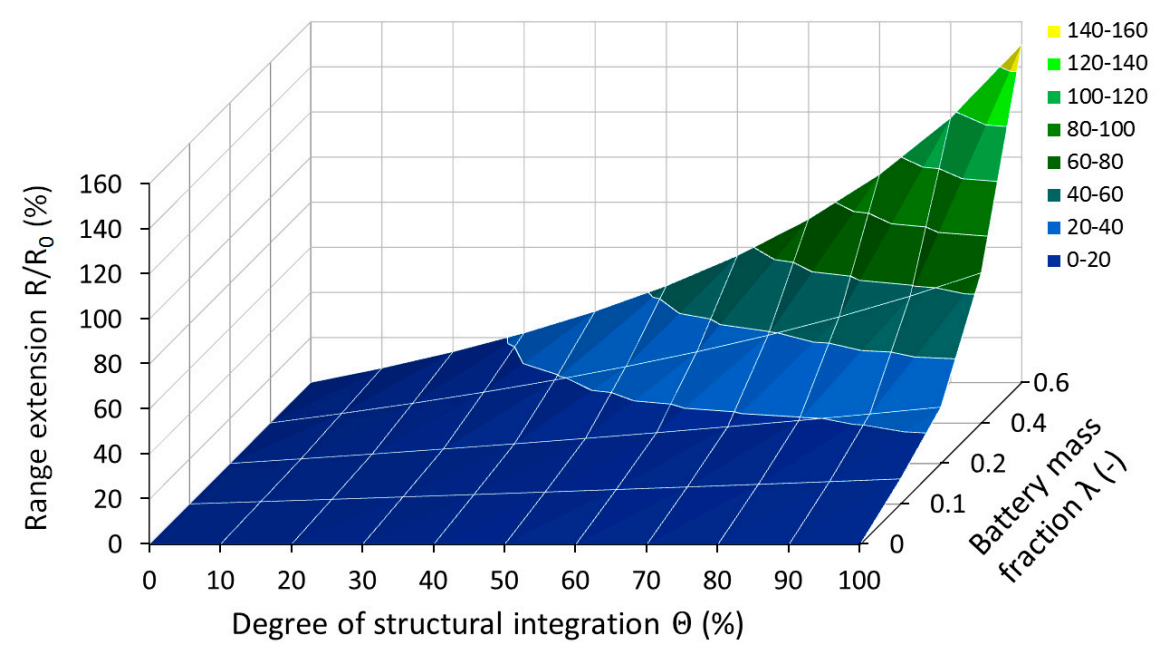

Figure 3. Theoretical aircraft cruise range extensions enabled by multifunctional energy-storing composites in dependence on the degree of structural integration and the ratio of battery and overall aircraft mass.

In addition to the possibility to reduce the system mass, there are several other general advantages relevant for technical applications. The structural integration can also provide significant volume savings which is especially interesting for small space vehicles (e.g., satellites). Utilization of space and cavities by integrating shape-adjusted storages into structural components is an important aspect as well. Furthermore, solid electrolyte-based composites provide safety benefits (in case of mechanical or thermal damage) compared to conventional cells such as lithium-ion batteries based on liquid electrolytes. They are less sensitive to local damage for example caused by mechanical penetration or by impact of micrometeroids or orbital debris. Additionally, solid electrolytes based on ceramics or ionic liquids are flame retardant which can also improve the fire resistance of the energy-storing laminate and of the whole structure. Concerning the thermal management of high-power applications, heat is more effectively transferred out of the system when the storage surface is large and the thickness is low (e.g., energy-storing vehicle skin). In a holistic system design, the structural energy storage may be used to power distributed electric consumers (e.g., distributed propulsion). However, there are challenges as well. Besides the fact that both structural and electrical properties of today's structural composites are far from being technologically feasible, there are further difficulties and limitations concerning connectability (e.g., in case of single-layer multifunctionalization), wiring effort, impact of ambient and operation temperature on mechanical and electrical performance, electrical and mechanical reliability, maintainability, replaceability of degraded and damaged storage, or costs.

All in all, structural energy storage technology is still in its infancy, and the development of structural battery-powered aircrafts is a visionary long-term goal.

\section{Experiments, Materials and Methods}

When aiming for higher degrees of structural integration, for example of supercapacitors, one main challenge is the development and optimization of electrolytes which are solid and provide the mechanical properties required for load bearing; however, ion conductivity has to be high as well. Of course, which type of electrolyte material to use depends on the intended structural application of the composite material and on the degree of structural integration. Solid electrolytes for future design 
and fabrication of energy-storing structural fiber-reinforced laminates for e.g., lightweight aircraft applications, without question, have to be polymeric.

However, depending on the technical application, ceramic electrolytes may be an alternative, for example for realizing laminate-integrated energy storing thin-film devices (degree II). Although ceramic materials are brittle, they have quite interesting mechanical properties, such as high strengths and moderate densities (ceramics: $1 \mathrm{~g} / \mathrm{cm}^{3}$ to $6 \mathrm{~g} / \mathrm{cm}^{3}$, GFRP: $2.1 \mathrm{~g} / \mathrm{cm}^{3}$, CFRP: $1.5 \mathrm{~g} / \mathrm{cm}^{3}$ ). Therefore, in the recent work, the ceramic electrolyte $\mathrm{Li}_{1.4} \mathrm{Al}_{0.4} \mathrm{Ti}_{1.6}\left(\mathrm{PO}_{4}\right)_{3}$ (LATP) was synthesized and integrated into a GFRP (glass fiber-reinforced polymer) composite laminate. Because of fabrication issues and the brittleness of the material, no thin films but electrolyte pellets were used for the first preliminary experiments. Regarding the degree of integration, pellet integration can be classified as type II, although it is quite different from the interlayer approach. However, all components of the capacitor were solid, they were bonded to the GFRP laminate, they were within the load path, and they were capable of carrying loads. The chosen method of integration, in fact, is just a first step, focusing on manufacturing challenges, electric contacting, the mechanical behavior of the integrated pellets, and their bonding. In addition to characterizing the energy-storing performance of the unloaded composite, the impact of mechanical loads is investigated.

\subsection{Synthesis Process of the $\mathrm{Li}_{1.4} A l_{0.4} \mathrm{Ti}_{1.6}\left(\mathrm{PO}_{4}\right)_{3}$ (LATP) Solid Electrolyte}

The $\mathrm{Li}_{1.4} \mathrm{Al}_{0.4} \mathrm{Ti}_{1.6}\left(\mathrm{PO}_{4}\right)_{3}$ (LATP) solid electrolyte was synthesized by a sol-gel method with citric acid. Stoichiometric amounts of $0.8 \mathrm{~mol} / \mathrm{L}$ Titanium (IV) t-butoxide ( $\geq 99.9 \%$, Alfa Aesar/Thermo Fisher Scientific Inc., Waltham, MA, USA) were dissolved in $0.2 \mathrm{~mol} / \mathrm{L}$ citric acid (>99\%, Merck KGaA, Darmstadt, Germany), heated and stirred at $95{ }^{\circ} \mathrm{C}$ for $20 \mathrm{~h}$. Then, stoichiometric amounts of $\mathrm{LiNO}_{3}$ ( $>99 \%$, ReagentPlus ${ }^{\circledR}$ via Merck KGaA, Darmstadt, Germany), $\mathrm{NH}_{4} \mathrm{H}_{2} \mathrm{PO}_{4}\left(>98.5 \%\right.$, ReagentPlus ${ }^{\circledR}$ via Merck KGaA, Darmstadt, Germany) and $\mathrm{Al}\left(\mathrm{NO}_{3}\right)_{3} \cdot 9 \mathrm{H}_{2} \mathrm{O}$ (99.2\%, VWR International LCC, Radnor, $\mathrm{DE}, \mathrm{USA}$ ) were added, dissolved, and stirred at the same temperature for $30 \mathrm{~min}$ until a homogeneous solution was obtained. After that, ethylene glycol ( $\geq 99.9 \%$, Merck KGaA, Darmstadt, Germany) with a molar ratio of citric acid of 1:1 was added. Then, the solution was heated up to $120^{\circ} \mathrm{C}$ with stirring for 30 min using a magnetic stirrer (MR 3003 control, Heidolph Instruments GmbH \& Co. KG, Schwabach, Germany). Afterwards, it was heated up to $170{ }^{\circ} \mathrm{C}$ for $2 \mathrm{~h}$ to evaporate the water and obtain the polymer precursor. The dried gel was milled by hand to a powder and transferred to a ceramic crucible. Then, it was heated up to $600{ }^{\circ} \mathrm{C}$ for $5 \mathrm{~h}$ (heating rate: $5^{\circ} \mathrm{C} / \mathrm{min}$ ) to complete the pyrolysis process, and subsequently submitted to open air calcination at $800^{\circ} \mathrm{C}$ for $5 \mathrm{~h}$. The acquired powder was milled with ethanol for $2 \mathrm{~h}$ using a ball mill (Pulverisette 7 premium line, Fritsch GmbH, Markt Einersheim, Germany). Afterwards, it was pressed into pellets (thickness: $1 \mathrm{~mm}$, mass: $0.25 \mathrm{~g}$ ) under the pressure of $180 \mathrm{MPa}$ (Atlas manual 25 tons hydraulic press GS25011, Specac Ltd., Orpington, UK). The pellets were sintered at $950{ }^{\circ} \mathrm{C}$ for $8 \mathrm{~h}$ (heating rate from ambient temperature to $600{ }^{\circ} \mathrm{C}$ was $2{ }^{\circ} \mathrm{C} / \mathrm{min}$, from $600{ }^{\circ} \mathrm{C}$ to $950{ }^{\circ} \mathrm{C}$ it was $\left.5^{\circ} \mathrm{C} / \mathrm{min}\right)$.

\subsection{Manufacturing of $\mathrm{Li}_{1.4} A \mathrm{l}_{0.4} \mathrm{Ti}_{1.6}\left(\mathrm{PO}_{4}\right)_{3}$ Solid Electrolyte-Based Multifunctional Composites}

The schematic architecture of an LATP composite specimen is depicted in Figure 4a. The unidirectional GFRP prepreg (Hexply ${ }^{\circledR}$ 913, Hexcel ${ }^{\circledR}$ Corporation, Stamford, CT, USA) was used for both the core laminate and the top and bottom cover laminates. The core laminate was made of eight layers GFRP prepreg with a ply thickness of $0.125 \mathrm{~mm}$ (Figure 4c). The layup was symmetric with the two outer layers oriented in $0^{\circ}$ direction, while the internal layers were alternately oriented at $0^{\circ}$ and $90^{\circ}$. For embedding the LATP pellet, a hole was punched in each unidirectional ply prior to stacking. Before placing the electrolyte pellets, their faces were polished and sputtered with gold to a thickness of about $90 \mathrm{~nm}$ to obtain the electrodes. Metalized polyester layers were used as electric conductive materials. Copper solder joints were integrated for later connecting the supercapacitor to measurement equipment (b). Then, two cover laminates stacks consisting of four layers each $\left(0^{\circ}\right.$ and $\left.90^{\circ}\right)$ were placed. All specimens were manufactured by hand using a one-step curing process 
under pressure ( $3 \mathrm{~h}, 120^{\circ} \mathrm{C}$ at $\left.3 \mathrm{bars}\right)$. After curing, the plate was cut into specimens for tensile tests according to DIN EN ISO 527-4 [51] (250 $\mathrm{mm} \times 25 \mathrm{~mm} \times 2 \mathrm{~mm})$ and for four-point bending tests based on DIN EN ISO 14125 [52]. In the case of the bending tests, the specimen geometry and supporting lengths (outer: $60 \mathrm{~mm}$, inner: $20 \mathrm{~mm}$ ) had to be adapted because of the pellet dimensions and the wiring. Figure $4 \mathrm{~d}$ shows an exemplary four-point bending specimen with copper-soldering contacts and the pellet position indicated.

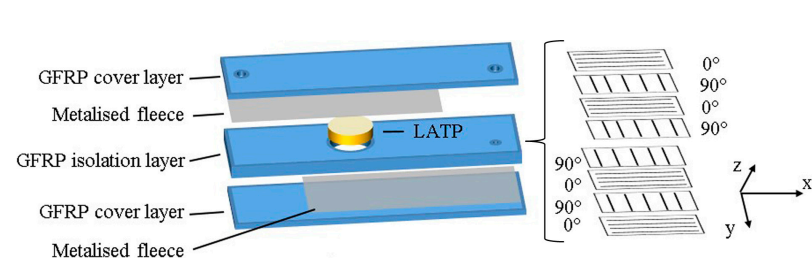

(a)

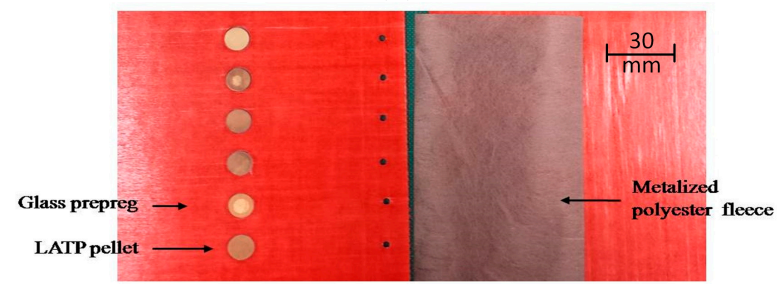

(c)

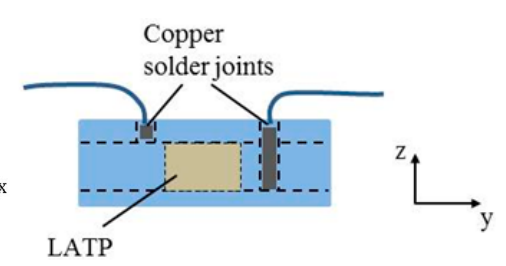

(b)

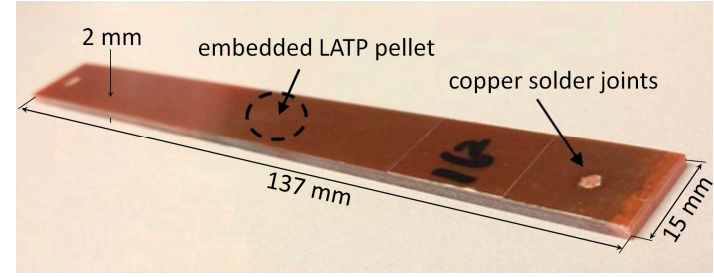

(d)

Figure 4. (a) Architecture of the LATP-GFRP composite; (b) electrical connectors; (c) core laminate with embedded LATP pellets; (d) four-point bending test specimen with bond points for electrical measurements.

\subsection{Characterization of Microstructure, Electrical, and Mechanical Properties}

A computerized tomography scan (CT, GE phoenix v l tome I x s, GE Measurement \& Sensing Technologies $\mathrm{GmbH}$, Gelsenkirchen, Germany) was generated to investigate the morphologic conditions of the LATP composite samples before the mechanical tests.

A cyclic voltammetry $(\mathrm{CV})$ test and galvanostatic charge-discharge measurements were conducted at room temperature by means of an electrochemical workstation (Vertex, IVIUM TECHNOLOGIES, Eindhoven, Netherlands) for the LATP composite samples, without and under mechanical load. The CV measurements were carried out in a voltage range between $0.0 \mathrm{~V}-0.5 \mathrm{~V}$ by CV with different scan rates of $5 \mathrm{mV} / \mathrm{s}, 10 \mathrm{mV} / \mathrm{s}, 20 \mathrm{mV} / \mathrm{s}, 50 \mathrm{mV} / \mathrm{s}$, and $100 \mathrm{mV} / \mathrm{s}$, and the galvanostatic charge-discharge measurements with different current densities of $0.1 \mu \mathrm{A} / \mathrm{g}, 0.2 \mu \mathrm{A} / \mathrm{g}, 0.5 \mu \mathrm{A} / \mathrm{g}$, $0.8 \mu \mathrm{A} / \mathrm{g}, 1 \mu \mathrm{A} / \mathrm{g}, 2 \mu \mathrm{A} / \mathrm{g}, 3 \mu \mathrm{A} / \mathrm{g}, 4 \mu \mathrm{A} / \mathrm{g}$, and $5 \mu \mathrm{A} / \mathrm{g}$. To verify the cyclic stability, 1500 charge-discharge cycles were accomplished with a current density of $2 \mu \mathrm{A} / \mathrm{g}$.

The mechanical properties were investigated by means of four-point bending tests (Figure $5 a$ ) and tensile tests (Figure 5b) using a universal testing machine (Zwick 1484, Zwick GmbH \& Co. KG, Ulm, Germany). Both tests were conducted with a displacement rate of $1 \mathrm{~mm} / \mathrm{min}$ and a preload of $5 \mathrm{~N}$ to ensure that the specimens were in a defined initial state. A $20 \mathrm{kN}$ load cell (Z4, Hottinger Baldwin Messtechnik GmbH, Darmstadt, Germany) and a displacement transducer were used. The force and deformation were recorded with the testing machine specific software Test-Expert II V3.31 (Zwick GmbH \& Co. KG, Ulm, Germany).

For electrochemical analyses during the mechanical tests, the specimens were connected to the electrochemical workstation. A step bending load was applied in the four-point bending tests. With an interval of $120 \mathrm{MPa}$, the static electrical properties were tested at loads of $120 \mathrm{MPa}, 240 \mathrm{MPa}, 360 \mathrm{MPa}$, $480 \mathrm{MPa}$, and $600 \mathrm{MPa}$. The combined tension tests were executed under step tension load with an interval of $60 \mathrm{MPa}$ applying distinct loads of $60 \mathrm{MPa}, 120 \mathrm{MPa}, 240 \mathrm{MPa}, 300 \mathrm{MPa}$, and $360 \mathrm{MPa}$. 


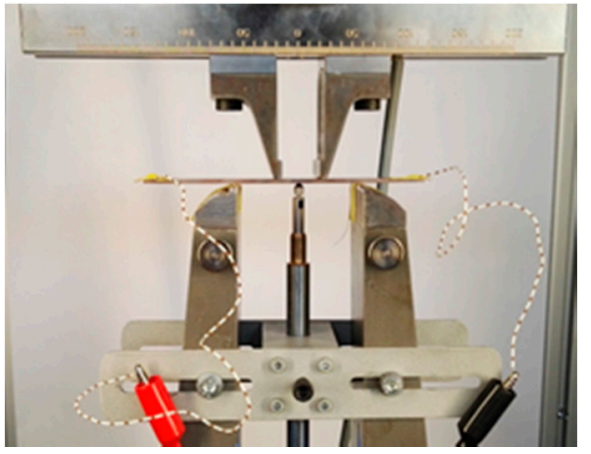

(a)

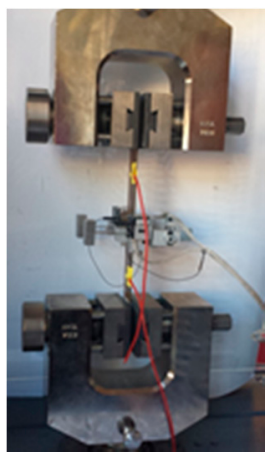

(b)

Figure 5. (a) Four-point bending test setup; (b) Tensile test setup.

\subsection{Data Evaluation}

\subsubsection{Capacitance Calculation}

Galvanostatic charge-discharge tests were executed by charging and discharging (charge $Q$, $[Q]=C)$ the device in between a potential window $(U,[U]=V)$ with a constant current $(I,[I]=\mathrm{A})$ and by recording the time of the corresponding process $(\Delta t,[\Delta t]=\mathrm{s})$. The specific capacitance $\left(\mathrm{C}_{\mathrm{m}}=\mathrm{C} / \mathrm{m}\right.$, $\left[\mathrm{C}_{\mathrm{m}}\right]=\mathrm{F} / \mathrm{g}$ ) was then calculated by means of Equation (14) [53]:

$$
C=\frac{Q}{U}=\frac{I \Delta t}{\Delta U}
$$

\subsubsection{Bending Strength and Young's Modulus Calculation}

The bending strength $\Phi(\mathrm{MPa})$ and the flexural modulus $E_{f}(\mathrm{MPa})$ of the specimens were calculated by means of the specimen geometry (length $L(\mathrm{~mm})$, width $b(\mathrm{~mm})$, thickness $h(\mathrm{~mm})$ ), the force $F(\mathrm{~N})$, and the displacement $s(\mathrm{~mm})$ recorded during the four-point bending test. According to DIN EN ISO 14125 [52] the equations are:

$$
\begin{gathered}
\Phi=\frac{F L}{b h^{2}} \\
E_{f}=\frac{0.21 L^{3}}{b h^{3}}\left(\frac{\Delta F}{\Delta s}\right)
\end{gathered}
$$

According to DIN EN ISO 527-4 [51], the tensile stress $\sigma$ (MPa) and the Young's modulus $E$ (MPa) were calculated by means of the strain $\varepsilon(-)$ and the force $F(\mathrm{~N})$ measured in the tensile tests. The calculated moduli refer to a strain range between $0.05 \%$ and $0.25 \%$.

$$
\begin{gathered}
\sigma=\frac{F}{A} \\
E=\frac{\sigma_{2}-\sigma_{1}}{\varepsilon_{2}-\varepsilon_{1}}
\end{gathered}
$$

\section{Results and Discussions}

\subsection{Morphological Investigations}

In order to investigate the quality of the LATP pellets and their embedding into the GFRP laminate, before-and-after CT scanning was conducted. Figure 6 depicts three cross sections $(a-c)$ of a bare pellet (upper row) and after embedding into GFRP (lower row). Figure 6a shows the $x y$-cross section at half the thickness. No macrofractures, inclusions, or other voids could be seen in the bare pellet. However, 
the slight grayscale variation suggests a certain inhomogeneity of the composition. The two darker dots are artefacts of the specimen holder.

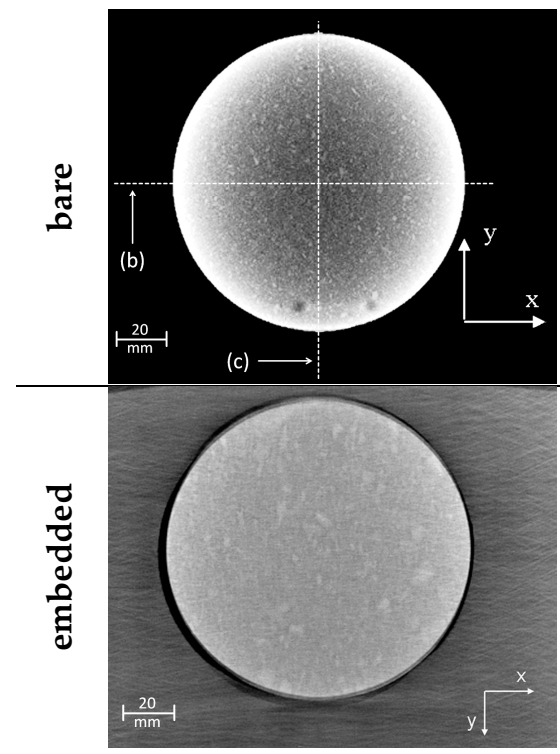

(a)

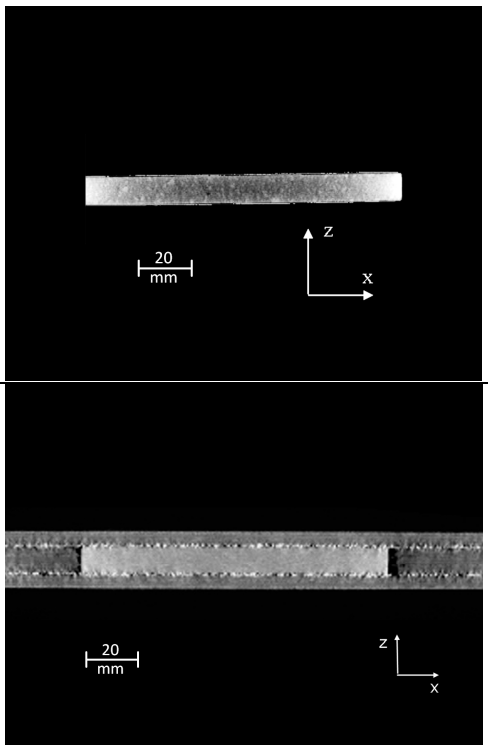

(b)

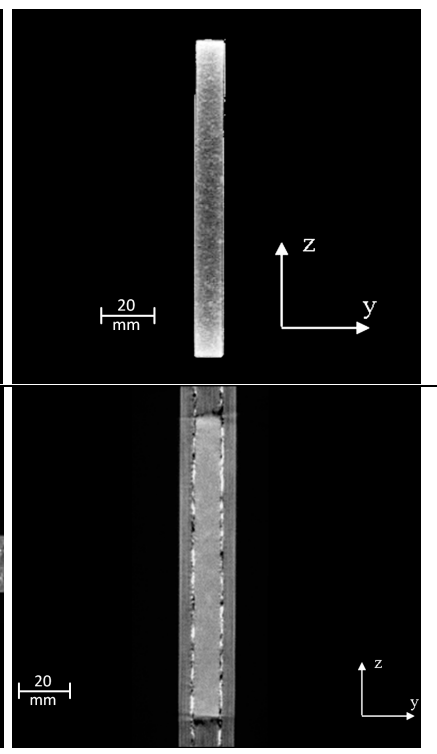

(c)

Figure 6. CT Images showing a bare pellet (upper row) and an embedded pellet (lower row): (a) $x y$-cross section; (b) $x z$-cross section; (c) $y z$-cross section.

The other cross sections (b: $x z$ and c: $y z$ ) did not show any visible defects, either. After embedding, a black circular region could be seen around the pellet (a). This region is a matrix-filled gap resulting from the loose fit of the pellet in the punched hole. The fiber-reinforced zones, in contrast, appeared gray. In the other cross sections of the embedded pellet, the metallized polyester fleece (light gray-white) could be identified. As no visible damage of the pellet could be seen in the CT scans, it may be concluded that autoclave processing did not affect the pellet integrity. Furthermore, neither the core or cover laminates nor the fleece layers showed any thickness variations or waviness. Except for the circular matrix-filled transition regions, the LATP-GFRP composition was of adequate quality.

\subsection{Electrochemical Measurements}

Cyclic voltammetry curves of the LATP electrical energy storage system are shown in Figure 7. The measurements were conducted at an ambient temperature of $24{ }^{\circ} \mathrm{C}$, between potentials from 0 to $0.5 \mathrm{~V}$ and at a scan rate of $5-100 \mathrm{mV} / \mathrm{s}$. In this potential range no visible peaks were observed, indicating the absence of faradaic current. This revealed that charge and discharge occurred reversibly at the Au-LATP interface. The curves were closer to a rectangular shape at lower scan rates $(5-20 \mathrm{mV} / \mathrm{s})$ and tended to tilt towards the vertical axis for scan rates above $20 \mathrm{mV} / \mathrm{s}$. Because of the slow chemical process of ion diffusion, the material heated up with an increasing scan rate (ohmic behavior), which resulted in both a tilting graph and current peaks at the maximum voltage.

To investigate the storage ability of the LATP electrical energy storage device, galvanostatic charge-discharge measurements were conducted with multiple charge-discharge current densities from 0.1 to $5 \mu \mathrm{A} / \mathrm{g}$ (Figure 8a). Only a slight voltage drop caused by internal resistance could be observed at a charge-discharge current density of $0.1 \mu \mathrm{A} / \mathrm{g}$ during discharge. The specific capacitances were calculated from the discharge curves and plotted in Figure 8b. At values lower than $1 \mu \mathrm{A} / \mathrm{g}$, the specific capacitance decreased rapidly with the increasing current density. At values higher than $2 \mu \mathrm{A} / \mathrm{g}$, the specific capacitance asymptotically approached a constant value below $10 \mu \mathrm{A} / \mathrm{g}$. The highest specific capacitance about $35.98 \mu \mathrm{F} / \mathrm{g}$ was reached at a current density of $0.1 \mu \mathrm{A} / \mathrm{g}$. 
Regarding the charge-discharge tests it was observed that the mean capacitance remained constant during 1500 cycles $(0-0.5 \mathrm{~V}, 2 \mu \mathrm{A} / \mathrm{g})$, as shown in Figure 8c.

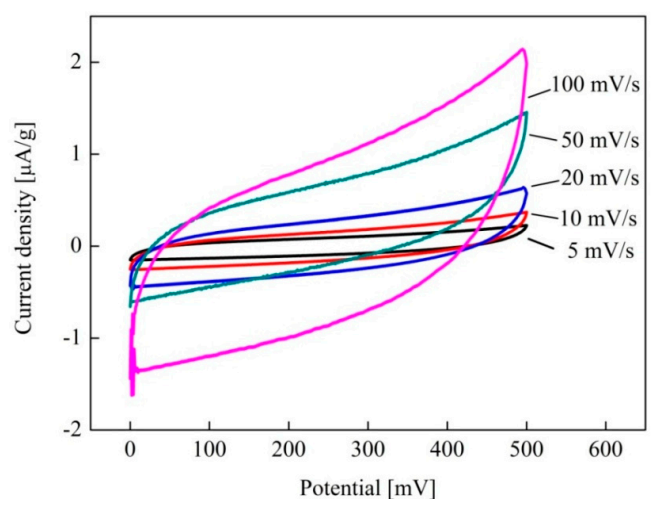

Figure 7. Cyclic voltammetry curves of the LATP sample measured with different scan rates.

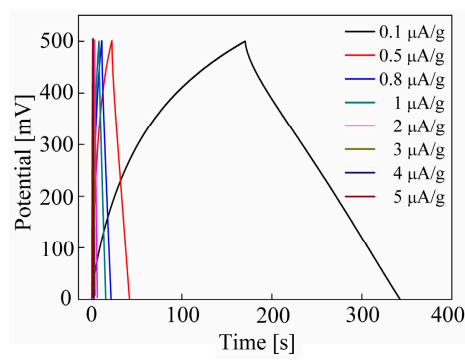

(a)

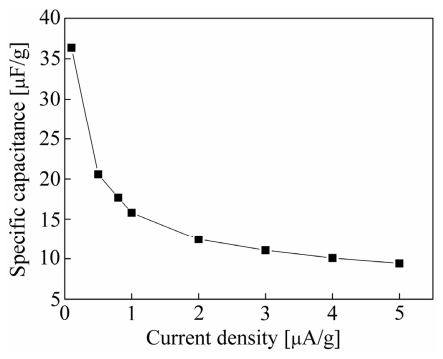

(b)

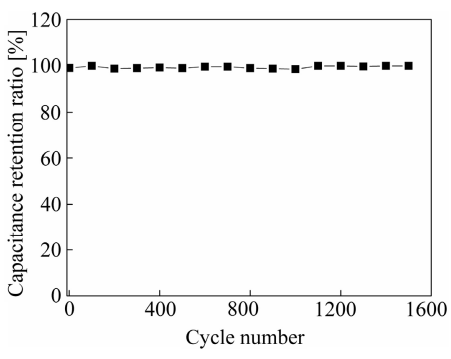

(c)

Figure 8. (a) Galvanostatic charge-discharge curves of the LATP composite with different current densities; (b) specific capacitances of LATP calculated from galvanostatic charge-discharge measurements; (c) change of capacitance during 1500 cycles of charge-discharge using a potential range of $0-0.5 \mathrm{~V}$ and a current density of $2 \mu \mathrm{A} / \mathrm{g}$.

\subsection{Mechanical Tests and Failure Modes}

The solid electrolyte $\mathrm{Li}_{1.4} \mathrm{Al}_{0.4} \mathrm{Ti}_{1.6}\left(\mathrm{PO}_{4}\right)_{3}$ features the typical mechanical properties of ceramic materials: it is very stiff but brittle. On the contrary, resins used as a matrix, and glass fibers used as reinforcements are usually much more flexible. When embedding the ceramic pellets into the composite, the fibers are cut, and a geometrical discontinuity is introduced. Consequently, embedding a pellet is assumed to affect the mechanical properties of the neat composites. In order to investigate this impact, four-point bending tests were performed to evaluate the flexural stiffness and strength, as well as the flexural failure modes of the LATP composites. In addition, the load transfer and integrity of the junction between the LATP ceramic elements and the polymer matrix were investigated by means of tensile tests. Besides determining the elastic properties, the tests were carried out until specimen failure to investigate the maximum stresses and strains at rupture, as well as the failure mechanisms.

\subsubsection{Mechanical Properties}

Figure 9a shows the displacement-stress curves of one representative specimen per type tested in the four-point bending tests. In the beginning, the bending stress was found to increase nearly linearly with the deformation, indicating a linear elastic material behavior. With increasing deformation, the stress-displacement behavior became non-linear before reaching the final rupture. Whereas the LATP-GFRP curve overlapped the reference curve at the beginning, the overall slope of the linear elastic range was slightly lower. Finally, with both maximum strain and stress at rupture being lower, 
failure occurred earlier compared to the reference specimen. The strain-stress curves gained in the tensile tests are depicted in Figure $9 \mathrm{~b}$. The whole reference curve tends to be a straight line, again indicating a linear elastic deformation behavior. The curve of LATP-GFRP is similar except for the lower slope and the lower tensile stress.

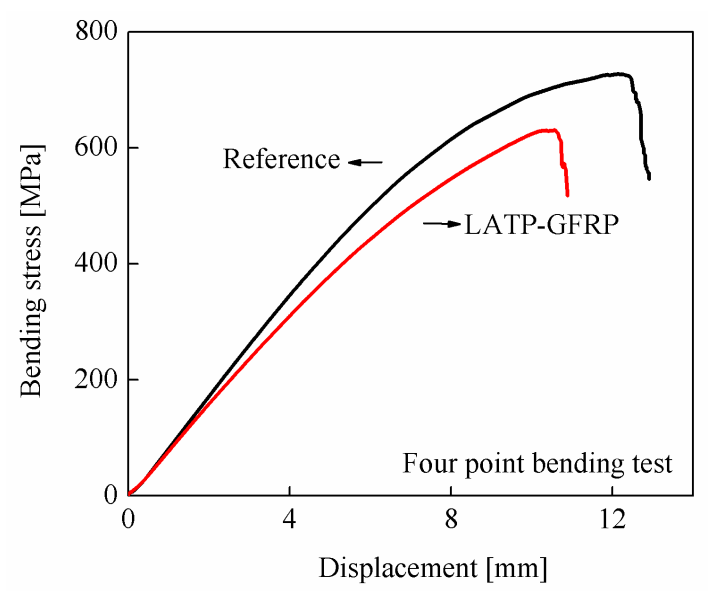

(a)

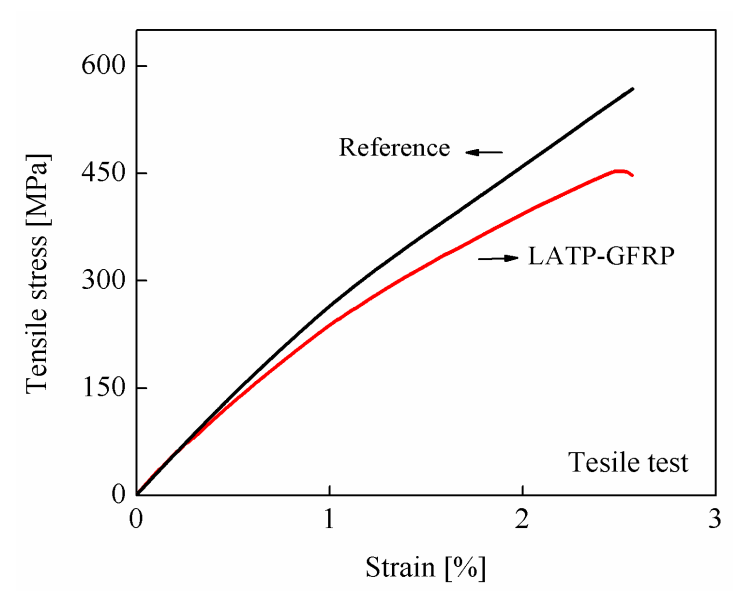

(b)

Figure 9. (a) Curves of four-point bending tests; (b) curves of tensile tests of the GFRP composite specimens with and without LATP pellets.

The calculated strength and elastic moduli, as well as the strain at rupture are summarized in Table 1. All given results are average values of two to four specimens. The results indicate that the embedding of LATP did not have significant effects on the Young's modulus, which changed from 29.77 GPa to 27.65 GPa (-7.1\%) under four-point bending and from 28.89 GPa to 27.10 GPa $(-6.2 \%)$ under tension. Furthermore, the LATP-GFRP specimens showed a lower strength compared to the reference value. The strength was found to decrease of about $11.5 \%$ in the four-point bending tests (GFRP: 735.11 MPa, LATP: 650.62) and of about 19.2\% under tension (GFRP: 565.1 MPa, LATP: 456.4 MPa). The underlying reasons are the unconformity of the mechanical properties of LATP and GFRP and the weak net section (interrupted fibers). Furthermore, the local change in stiffness causes stress peaks which promote damage initiation.

Table 1. Summary of the experimentally characterized mechanical properties of LATP-GFRP.

\begin{tabular}{ccccccc}
\hline & \multicolumn{2}{c}{ Four-Point Bending Test (4 Specimens) } & \multicolumn{2}{c}{ Tensile Test (2 Specimens) } \\
\cline { 2 - 6 } & $\begin{array}{c}\text { E-Modulus } \\
\mathbf{( M P a )}\end{array}$ & $\begin{array}{c}\text { Strength } \\
\mathbf{( M P a )}\end{array}$ & $\begin{array}{c}\text { Strain at } \\
\text { Rupture (\%) }\end{array}$ & $\begin{array}{c}\text { E-Modulus } \\
\mathbf{( M P a )}\end{array}$ & $\begin{array}{c}\text { Strength } \\
\mathbf{( M P a )}\end{array}$ & $\begin{array}{c}\text { Strain at } \\
\text { Rupture (\%) }\end{array}$ \\
\hline Reference & $29770 \pm 1918$ & $735 \pm 31$ & $3.03 \pm 0.04$ & 28896 & 565.1 & 2.57 \\
LATP-GFRP & $27651 \pm 3907$ & $651 \pm 26$ & $2.66 \pm 0.05$ & 27104 & 456.4 & 2.53 \\
Ratio & $92.9 \%$ & $88.5 \%$ & $87.8 \%$ & $93.8 \%$ & $80.8 \%$ & $98.4 \%$ \\
\hline
\end{tabular}

\subsubsection{Failure Behavior}

Because of the different materials (LATP, metallized polyester fleece, GFRP), the way of structural integration of the pellet, and the mismatch of the mechanical properties, the damage and failure behavior of the LATP composite is rather complex. With the pellet being much stiffer than the embedding composite material, a non-linear stress-strain field forms around the pellet. With the composite material undergoing much higher deformations e.g., under uniaxial longitudinal tension, tension and compression stress and strain fields occur under angles of $0^{\circ}$ (longitudinal direction: 
tension) and $90^{\circ}$ (transverse direction: local compression due to the suppression of the lateral contraction).

Figure 10 shows multiperspective damage state photographs of an exemplary tension specimen after mechanical testing. A prerupture photo (a) was taken at about $64 \%$ of the ultimate load to obtain an impression of the damage evolution. Front, back, and side views of the ruptured specimen are depicted in Figure 10b. It was observed that the delamination initiated at the tips of the pellet oriented in a longitudinal direction (a). The local delamination initiation and progression were caused by the stiffness mismatch of the neighboring materials, presumably a low interfacial adhesion and post-initiation shear-lag effects. In the picture, the pellet is presumably delaminated completely, although the dark square coinciding with the pellet does not indicate any delamination.

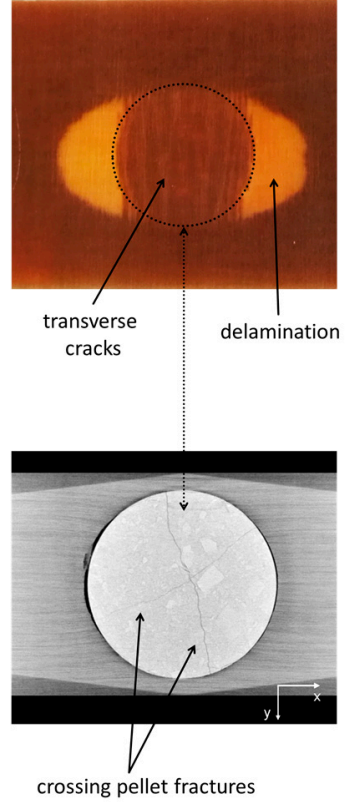

(a)

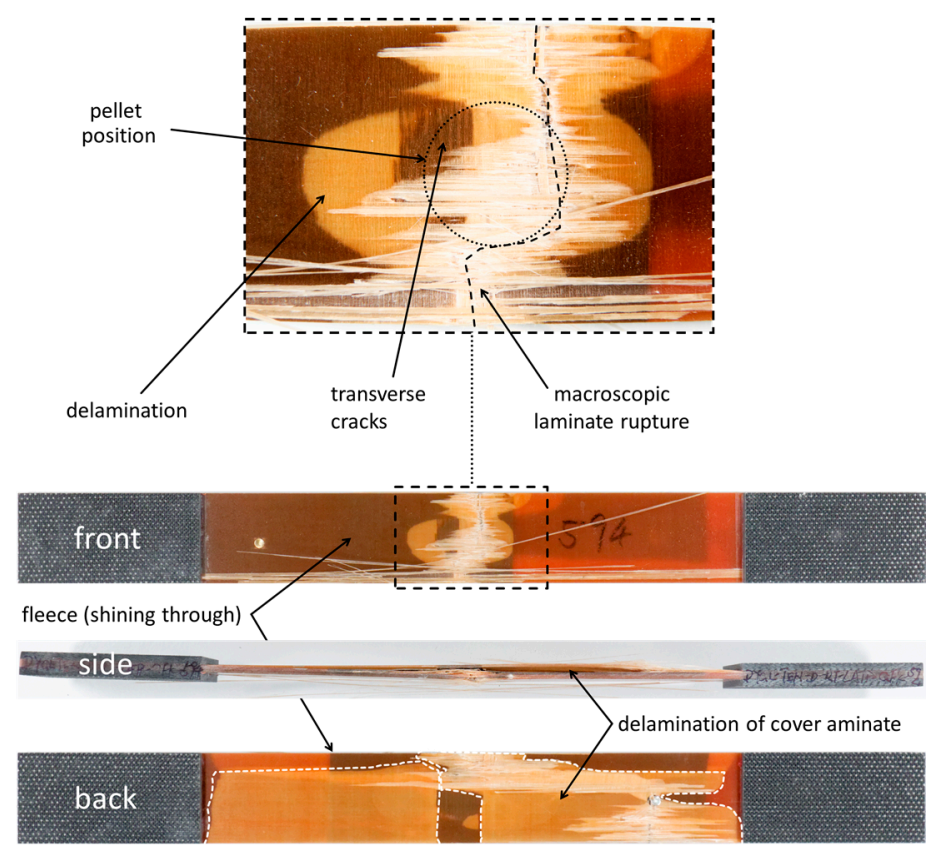

(b)

Figure 10. Exemplary LATP-GFRP tension specimen after mechanical testing: (a) surface photo of the specimen and CT image of the embedded pellet at about $64 \%$ of the ultimate load; (b) front, side, and back views of the same specimen after final failure.

Post-rupture investigations revealed that the dark region was due to a change of the delamination plane occurring at the tips of the pellet. With the polyester fleece delaminating from the pellet surface, the cover sublaminate appeared dark. The brighter areas, in contrast, were due to local interfacial debonding of the cover laminate and the metalized polyester fleece. As the net section was highly stressed after pellet debonding, a local transverse cracking occurred. At this state, the specimen was removed from the testing machine to investigate the condition of the pellet by means of CT. The CT image revealed that the pellet was already cracked, although the specimen was far from final failure. Contrary to the expectations, two crossing fractures instead of one transverse cleavage fracture were observed. This is presumably caused by the brittleness of the material and the combination of longitudinal tension and lateral compression. Whereas the applied longitudinal load was assumed to have caused the transverse separation, the angled crack was presumably caused by the lateral contraction- and compression-induced shear failure. A further increase of the tension load led to a final macroscopic net section rupture dominated by fiber failure. The macroscopic laminate rupture, split-off fiber bundles $\left(0^{\circ}\right)$, and delamination of the cover laminate can be seen in the magnification of the front side of the specimen. In contrast to the front side, a widespread debonding of the cover 
laminate can be seen on the back side and in the side view. Again, the cover laminate delamination was caused by adhesive failure of the metallized polyester fleece.

Concerning the four-point bending failure behavior, several similarities exist compared to the tension tests. Because of the symmetrical layup, it can be assumed that the bending neutral axis is located in the midplane of the specimen. Thus, the upper side compression and the lower side tensile stresses are assumed to be of comparable value. Again, three perspectives (tension side view, side view, compression side view) are illustrated in Figure 11.

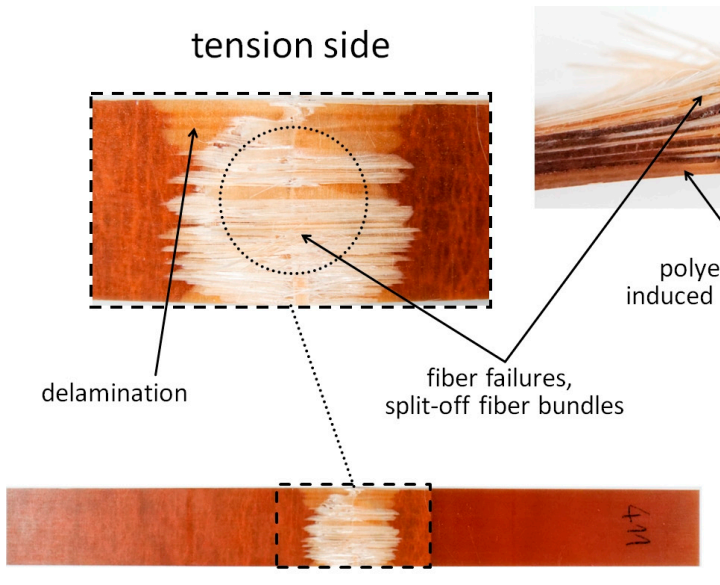

(a)
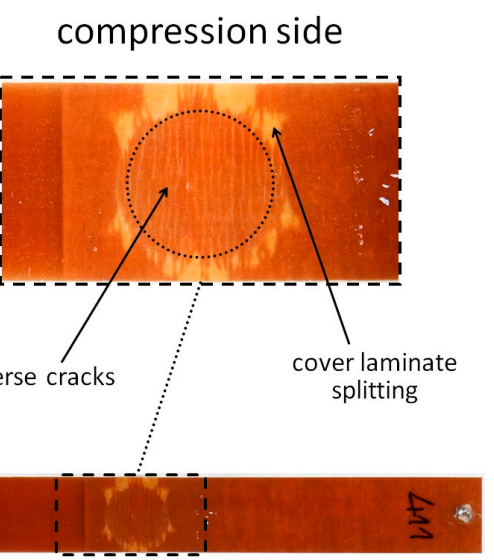

(c)

Figure 11. Surface photographs of an exemplary ruptured LATP-GFRP four-point bending specimen, tension side view (a), side view (b), and compression side view (c).

Whereas thin transverse cracks and slight interlaminar delamination were observed on the compression side, the tension caused predominating fiber rupture and delamination. Similar to the rupture behavior observed in the tensile tests, the fiber bundles split off because of an elastic energy discharge at the moment of fiber fracture. Additional to the extensive fiber failure on the tension side, a slight interfacial delamination of the polyester fleece layer could be identified (brighter) on the compression side. The delaminated cover laminate showed an additional internal delamination as well as slight transverse cracks caused by the compression of the net section. Because of the extent of damage, all specimens showed a permanent deformation after removing the load.

\subsection{Impact of Mechanical Loads on the Capacitance}

As illustrated in Figure 12a, the capacitance of LATP-GFRP decreased slightly (capacitance retention ratio changes from 98 to $93 \%$ ) when the bending stress was increased from 120 to $600 \mathrm{MPa}$. The apparent capacitance degradation was, in fact, assumed to be caused by contact loss due to delamination between the metalized polyester fleece and the LATP pellet under bending loads.

In the tensile tests, the capacitance of LATP-GFRP (Figure 12b) increased about $67 \%$ in the first step of tensile load application. Afterwards, the capacitance decreased to the initial value when the load was increased further. Again, the capacity changes were assumed to result from changing the electrical contact conditions. As the longitudinal tension caused lateral contractions in the width and thickness directions, the distance between the conductive layer (metalized polyester fleece) and the pellet surface was decreased. With the effective distance, the contact resistance decreased as well. In contrast, local strains and damages were assumed to negatively affect the contact resistance towards higher loads. 


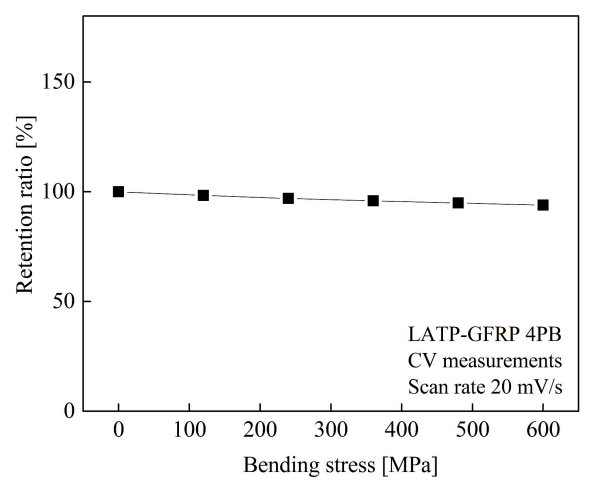

(a)

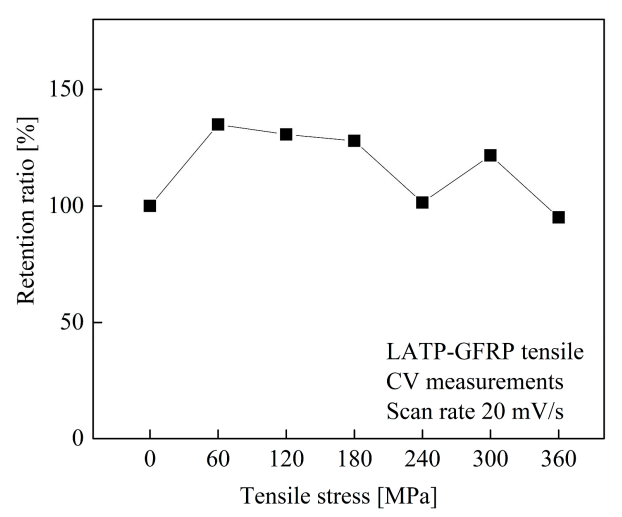

(b)

Figure 12. (a) LATP-GFRP with four-point bending test (4PB); (b) LATP-GFRP with tensile test; Values are averages from $2-3$ specimens.

\section{Conclusions and Outlook}

Regarding the benefits for aerospace applications, weight reduction clearly is the main driver for integrating energy storage into structure. Potential cruise range extensions of a battery-powered electric aircraft were assessed using a modified range equation. Range extensions up to $66 \%$ were predicted. However, to enable this, both the structural and electrical properties of today's energy storing laminates have to be significantly improved, and structural energy storage has to be capable of covering the conventional battery's capacity.

Concerning the existing approaches towards structural energy storage, five different ways of structural integration (functional separation (0), structurally integrated conventional storages (I), thin-film-based approaches (II), single-ply functionalization (III), functionalization of the constituents (IV)) can be distinguished. Two expressions, the degree of integration (0 to IV) and the scale of multifunctionalization were introduced for a more specific classification. From a theoretical point of view, the specific energy increases with the degree of integration and with the scale of multifunctionalization from the component level, over macro- and meso- to microscale. Concerning today's performance of structural energy storage, the literature study revealed that the low mechanical and electrochemical performances of state-of-the-art polymeric solid electrolytes are the most limiting factors for achieving high gravimetric energy densities. In fact, structural energy storage technology is still in the beginning, and commercial technical applications rely on conventional, monofunctional non-load-carrying energy storage devices. Regarding the existing structural energy storage concepts, lithium-based thin-film batteries show the best performance with respect to specific energy and power. However, their structural performance is low. In the medium term, solid electrolyte-based interlayer approaches with all components capable of carrying loads seem to be practicable. In the long term, the enhancement of energy-storing composite laminates based on constituent functionalization is assumed to be most promising to reach high-energy densities and adequate specific structural properties.

As ceramic solid-state electrolytes are an alternative regarding thin-film- or interlayer-based integration approaches, the electric and mechanical properties of an LATP-based energy storing composite were investigated. In a very first step, circular electrolyte pellets were fabricated and integrated into a GFRP laminate. The capacitance was measured by means of galvanostatic charge-discharge tests showing a specific capacitance value of $35.98 \mu \mathrm{F} / \mathrm{g}$ at $0.1 \mu \mathrm{A} / \mathrm{g}$. The capacitance was found to be constant over 1500 charge-discharge cycles. The mechanical properties of LATP composites and reference specimens were mechanically characterized by means of four-point bending and tensile tests. The interface regions between the LATP pellet and the polymer matrix awee observed to be the weakest areas in the composite, however, the embedding of the LATP pellets did not 
significantly affect the mechanical properties. The stability of the energy storing capability was proven by means of electromechanical coupling tests.

The so far realized integration of pellets has to be seen as a preliminary step towards a more compliant integration method. Thin LATP layers could be used to realize a degree II and even a degree III integration. Films with thicknesses below $200 \mu \mathrm{m}$ could be fabricated by means of high-temperature sintering or physical-vapor-deposition electroplating. Obviously, this would enhance the mechanical performance of a composite structure compared to the introduced method. For further improvements of the electrical resistivity between the collector and the electrode, as well as of the bonding between the electrolyte and the structural material, the direct deposition of the LATP onto the structural materials, e.g., fiber tows or fabrics, could be realized. Besides selective laser sintering, 3D ceramic printing might be a potential future fabrication method as well.

Acknowledgments: Tribute has to be paid to A. Viandier of the Technical University of Braunschweig, Institute of Adaptronics and Function Integration for providing her analyzing methods and expertise.

Author Contributions: Till Julian Adam organized the contents, conducted major parts of the literature research, estimated possible performance gains for electric flight and prepared and edited the overall manuscript. Guangyue Liao conducted the underlying scientific work including LATP specimen fabrication and experimental characterization (Sections 3 and 4) and contributed to the conclusion (Section 5). Jan Petersen contributed to the literature research (Sections 2.2.3-2.2.5) and the conclusion (Section 5). Sebastian Geier supported the evaluation of the experimental data. Benedikt Finke helped with the fabrication of the ceramic electrolyte. Peter Wierach, Arno Kwade, and Martin Wiedemann supervised the work and provided a number of key suggestions.

Conflicts of Interest: The authors declare no conflict of interest. The founding sponsors had no role in the design of the study; in the collection, analyses, or interpretation of data; in the writing of the manuscript, and in the decision to publish the results.

\section{References}

1. Moore, M.; Fredericks, B. Misconception of electric propulsion aircraft and their emergent aviation markets. In Proceedings of the 52nd AIAA Aerospace Sciences Meeting, National Harbor, MD, USA, 13-17 January 2014. [CrossRef]

2. Winkler. Siemens und das Verkehrswesen 1847-1922. Verkehrstechnik 1923, 2, 12.

3. Schrader, H. Deutsche Autos Band 1, 1885-1920, 1st ed.; Motorbuch Verlag: Stuttgart, Germany, $2002 ;$ p. 182. ISBN 3613022117.

4. $\quad$ Boschert, S. Plug-in Hybrids: The Cars that Will Recharge America, 1st ed.; New Society Publishers: Gabriola Island, BC, Canada, 2006; ISBN 0865715718.

5. The History of Electric Car. Available online: https:/ / energy.gov/articles/history-electric-car (accessed on 26 October 2017).

6. Hepperle, M. Electric Flight_Potential and Limitations, Energy Efficient Technologies and Concepts of Operation; Paper STO-MP-AVT-209; NATO Science and Technology Organization: Lisbon, Portugal, 2012.

7. Moulton, R. An electric aero-plane. Flight Int. 1973, 104, 946.

8. A Green Machine. Available online: http://www.boeing.com/news/frontiers/archive/2008/may/ts_sf04. pdf (accessed on 26 October 2017).

9. Taurus Electro. Available online: http://www.pipistrel.si/plane/taurus-electro/overview (accessed on 26 October 2017).

10. Our Story. Available online: http:/ / www.solarimpulse.com/our-story (accessed on 26 October 2017).

11. Airbus E-Fan the Future of Electric Aircraft. Available online: company.airbus.com/responsibility/airbus-efan-the-future-of-electric-aircraft.html (accessed on 26 October 2017).

12. EFusion. Available online: http:/ / magnusaircraft.com/efusion2/ (accessed on 26 October 2017).

13. Emissionsfreier Antrieb für die Luftfahrt: Erstflug des Viersitzigen Passagierflugzeugs HY4. Available online: http:/ / www.dlr.de/dlr/desktopdefault.aspx/tabid-10081/151_read-19469/ (accessed on 27 October 2017).

14. Electric Motor Sets Two Speed Records. Available online: siemens.com/press/en/pressrelease/2017/ corporate/pr2017040256coen.htm (accessed on 26 October 2017).

15. NASA's X-57 Electric Research Plane. Available online: nasa.gov/image-feature/nasas-X-57-electricresearch-plane/ (accessed on 26 October 2017). 
16. Asp, L.E.; Greenhalgh, E.S. Structural power composites. Compos. Sci. Technol. 2014, 101, 41-61. [CrossRef]

17. Snyder, J.F.; O'Brien, D.J.; Wetzel, E.D. Structural Batteries, Capacitors and Supercapacitors. In Handbook of Solid State Batteries, 2nd ed.; Dudney, N.J., West, W.C., Nanda, J., Eds.; World Scientific Publishing Co. Pte Ltd.: Singapore, 2015; pp. 657-699. ISBN 9814651893.

18. Liu, P.; Ross, R.; Newman, A. Long-range, low-cost electric vehicles enabled by robust energy storage. MRS Energy Sustain. 2015, 2, 1-13. [CrossRef]

19. Ladpli, P.; Nardari, R.; Kopsaftopoulos, F.; Wang, Y.; Chang, F.-K. Design of Multifunctional Structural Batteries with Health Monitoring Capabilites. In Proceedings of the 8th European Workshop on Structural Health Monitoring (EWSHM 2016), Bilbao, Spain, 5-8 July 2016.

20. Asp, L.E.; Leijonmarck, S.; Carlson, T.; Lindbergh, G. Realisation of Structural Battery Composite Materials. In Proceedings of the 20th International Conference on Composite Materials (ICCM 2015), Copenhagen, Denmark, 19-24 July 2015.

21. Aerocomposites: The Move to Multifunctionality. Available online: https:/ /www.compositesworld.com/ articles/aerocomposites-the-move-to-multifunctionality (accessed on 30 November 2017).

22. Thomas, J.P.; Qidwai, M.A. Mechanical design and performance of composite multifunctional materials. Acta Mater. 2004, 52, 2155-2164. [CrossRef]

23. Momoda, L.A. The Future of Engineering Materials: Multifunction for Performance-Tailored Structures. In Frontiers of Engineering: Reports on Leading-Edge Engineering from the 2004 NAE Symposium on Frontiers of Engineering; The National Academies Press: Washington, DC, USA, 2005; Volume 1, pp. 47-152. [CrossRef]

24. Qidwai, M.A.; Thomas, J.; Matic, P. Structure-battery multifunctional composite design. In Proceedings of the SPIE Conference on Smart Structures and Materials 2002: Industrial and Commercial Applications of Smart Structures Technologies, San Diego, CA, USA, 17-21 March 2002; Rivas McGowan, A.-M., Ed.; SPIE-Press: Bellingham, WA, USA, 2002; Volume 4698, pp. 180-191.

25. Christodoulou, L.; Venables, J.D. Multifunctional material systems: The first generation. J. Miner. Met. Mater. Soc. 2003, 55, 39-45. [CrossRef]

26. Gibson, R.F. A review of recent research on mechanics of multifunctional composite materials and structures. Compos. Struct. 2010, 92, 2793-2810. [CrossRef]

27. Wetzel, E.D. Reducing Weight: Multifunctional Composites Integrate Power, Communications, and Structure. AMPTIAC Q. 2004, 8, 91-95.

28. Robert, O.; Bhushan, L.; Karihaloo, I.; Milne, I. Comprehensive Structural Integrity: Fracture of Materials from Nano to Macro, 1st ed.; Elsevier: Amsterdam, The Netherlands, 2003; p. X. ISBN 0080437494.

29. Thomas, J.P.; Qidwai, W.R.; Pogue, W.R., III; Pham, G. Multifunctional Structure-Battery composites for marine systems. J. Compos. Mater. 2012, 47, 5-26. [CrossRef]

30. Thomas, J.P.; Keennon, M.T.; DuPasquier, A.; Qidwai, M.A.; Matic, P. Multifunctional Structure-Battery Materials for Enhanced Performance in Small Unmanned Air Vehicles. In Proceedings of the ASME 2003 International Mechanical Engineering Congress and Exposition Materials, Washington, DC, USA, 15-21 November 2003; pp. 289-292. [CrossRef]

31. Owens, B.B. Solid state electrolytes: Overview of materials and applications during the last third of the twentieth century. J. Power Sources 2000, 90, 2-8. [CrossRef]

32. Gasco, F.; Feraboli, P. Hybrid Thin Film lithium Ion-Graphite Composite Battery Laminates: An Experimental Quasi-static Characterization. J. Multifunct. Compos. 2013, 1, 49-70. [CrossRef]

33. Gasco, F.; Feraboli, P. Manufacturability of composite laminates with integrated thin film Li-ion batteries. J. Compos. Mater. 2014, 48, 899-919. [CrossRef]

34. Mullenax, J.; Browning, P.; Huebsch, W.; Gautam, M.; Sabolsky, E.M. Composite Multifunctional Lithium-Ion Batteries in ECS Trans. In Proceedings of the 220th ECS Meeting, Boston, MA, USA, 9-14 October 2011; Sunkara, M., Abraham, K., Smart, M., Brodd, R., Bugga, R., Eds.; The Electrochemical Society: Pennington, NJ, USA, 2012; Volume 41, pp. 175-185. [CrossRef]

35. Pereira, T.; Guo, Z.; Nieh, S.; Arias, J.; Hahn, T. Energy Storage Structural Composites: A Review. J. Compos. Mater. 2009, 43, 549-560. [CrossRef]

36. Pereira, T.; Guo, Z.; Nieh, S.; Arias, J.; Hahn, T. Embedding thin-film lithium energy cells in structural composites. Compos. Sci. Technol. 2008, 68, 1935-1941. [CrossRef]

37. Shirshova, N.; Qian, H.; Shaffer, M.S.P.; Steinke, J.H.G.; Greenhalgh, E.S.; Curtis, P.T.; Kucernak, A.; Bismarck, A. Structural composite supercapacitors. Compos. Appl. Sci. Manuf. 2013, 46, 96-107. [CrossRef] 
38. Qian, H.; Kucernak, A.; Greenhalgh, E.S.; Bismark, A.; Shaffner, M.S.P. Multifunctional structural power composites based on carbon aerogel modified high performance fabrics. In Proceeding of the 19th International Conference on Composite Materials (ICCM 19), Montreal, QC, Canada, 28 July-2 August 2013.

39. Greenhalgh, E.S.; Asp, L.E. Storage_Final Publishable Summary Report; Imperial College: London, UK, 2013.

40. Qian, H.; Diao, H.; Shirshova, N.; Greenhalgh, E.S.; Steinke, J.H.G.; Shaffer, M.S.P.; Bismarck, A. Activation of structural carbon fibres for potential applications in multifunctional structural supercapacitors. J. Colloid Interface Sci. 2012, 395, 241-248. [CrossRef] [PubMed]

41. Wong, E.L.; Baechele, D.M.; Xu, K.; Carter, R.H.; Snyder, J.F.; Wetzel, E.D. Design and processing of structural composite batteries. In Proceedings of the Society for the Advancement of Material and Process Engineering (SAMPE), Baltimore, MD, USA, 3-7 June 2007.

42. Asp, L.E. Multifunctional composite materials for energy storage in structural load path. Plast. Rubber Compos. 2013, 42, 144-149.

43. Yu, Z.; Thomas, J. Energy Storing Electrical Cabels: Integrating Energy Storage and Electrical Conduction. Adv. Mater. 2014, 26, 4279-4285. [CrossRef] [PubMed]

44. Leijonmarck, S.; Carlson, T.; Lindbergh, G.; Asp, E.S.; Maples, H.; Bismarck, A. Solid polymer electrolyte coated carbon fibers for structural and novel micro batteries. Compos. Sci. Technol. 2013, 149-157. [CrossRef]

45. Geiß, I.; Voit-Nitschmann, R. Sizing of fuel-based systems for electric aircrafts. Proc. IME G J. Aerosp. Eng. 2017, 231, 2295-2304. [CrossRef]

46. Patterson, M.; German, B. Performance Analysis and Design of On-Demand Electric Aircraft Concepts. In Proceedings of the 12th AIAA Aviation Technology, Integration, and Operations (ATIO) Conference and 14th AIAA/ISSMO Multidisciplinary Analysis and Optimization Conference, Aviation Technology, Integration, and Operations (ATIO) Conferences, Indianapolis, IN, USA, 17-19 September 2012. [CrossRef]

47. Patterson, M.; Daskilewicz, M.; German, B. Conceptual Design of Electric Aircraft with Distributed Propellers: Multidisciplinary Analysis Needs and Aerodynamics Modeling Development. In Proceedings of the 52nd Aerospace Sciences Meeting, AIAA SciTech Forum 2014, National Harbor, MD, USA, 13-17 January 2014. [CrossRef]

48. McDonald, R. Electric Propulsion Modeling for Conceptual Aircraft Design. In Proceedings of the 52nd Aerospace Sciences Meeting, AIAA SciTech Forum 2014, National Harbor, MD, USA, 13-17 January 2014. [CrossRef]

49. Frosina, E.; Caputo, C.; Marinaro, G.; Senatore, A.; Pascarella, C.; Lorenzo, G. Modelling of a hybrid-electric Light Aircraft. Energy Procedia 2017, 126, 1155-1162. [CrossRef]

50. Pornet, C.; Isikveren, A.T. Conceptual Design of hybrid-electric transport aircraft. Prog. Aerosp. Sci. 2015, 79, 114-135. [CrossRef]

51. ISO. DIN EN ISO 527-4:1997, Plastics—Determination of Tensile Properties_Part 4: Test Conditions for Isotropic and Anisotropic Fibre-Reinforced Plastic Composites (ISO 527-4:1997); German Version (EN ISO 527-4:1997); ISO: London, UK, 1997.

52. ISO. DIN EN ISO 14125:2011, Fibre-Reinforced Plastic Composites-Determination of Flexural Properties (ISO 14125:1998 + Cor.1:2001 + Amd.1:2011); German Version (EN ISO 14125:1998); ISO: London, UK, 2011.

53. IEC. DIN EN 62391-1:2016, Fixed Electric Double-Layer Capacitors for Use in Electric and Electronic Equipment_Part 1: Generic Specification (IEC 62391-1:2015); German Version (EN 62391-1:2016); IEC: London, UK, 2016.

(C) 2018 by the authors. Licensee MDPI, Basel, Switzerland. This article is an open access article distributed under the terms and conditions of the Creative Commons Attribution (CC BY) license (http://creativecommons.org/licenses/by/4.0/). 